\author{
Varja Cvetko Orešnik in Janez Orešnik \\ Filozofska fakulteta, Ljubljana
}

\title{
Slovenski oziralni odvisniki v naravni skladnji
}

V okviru naravne skladnje (ki je veja teorije naravnosti) se določajo predpostavke, na podlagi katerih se dajo napovedati nekatere razmere v slovenskih oziralnih odvisnikih. Selektivno so obravnavani oziralni odvisniki 1 . s $k i+$ oziralnonavezovalnim zaimkom, 2 . s kateri in 3 . z oziralnimi prislovnimi določili. Bistvena je raba vzporednega in križnega povezovanja med soodnosnimi vrednostmi v lestvicah naravnosti.

Natural Syntax (a branch of Naturalness Theory) defines presuppositions with whose help certain aspects of Slovenian relative clauses can be predicted. Selected instances of relative clauses featuring (1) ki + resumptive pronoun, (2) kateri, and (3) relative adverbials are treated. What is essential is the implementation, in the naturalness scales, of parallel and chiastic alignment of corresponding values.

Naravna skladnja je deduktivna jezikoslovna teorija (v razvoju), ki določa predpostavke, na podlagi katerih so neke (obliko)skladenjske razmere napovedljive - in tako na opisni ravnini razložene. Osnovna vrsta predpostavk so t. i. lestvice naravnosti in pravila povezovanja med soodnosnimi vrednostmi po dveh lestvic. (Obliko)skladenjske razmere so predstavljene v obliki med sabo primerljivih dvojnic. Naravna skladnja ne vsebuje nikakršne tvorbene sestavine.

Sledijo osnovna načela, s katerimi v okviru naravne skladnje določamo lestvice naravnosti. Na nekatera izmed njih se bova sklicevala v nadaljevanju:

(a) Načelo ugodnega za govorečega in ugodnega za ogovorjenega. Kar je ugodno za govorečega, je bolj naravno; govoreči je namreč središče sporazumevanja. Z lestvico: >nat (ugodno za govorečega, ugodno za ogovorjenega). Ta pogled na naravnost pozna jezikoslovje že dolgo (Havers 1931: 171), in sicer pod imenoma težnja po gospodarnosti (to izkorišča predvsem govoreči) in težnja po natančnosti (ta godi predvsem ogovorjenemu).

(b) Načelo najmanjšega napora (Havers 1931: 171). Kar se bolj sklada s tem načelom, je govorečemu bolj naravno. Kar je za govorečega kognitivno preprosto, se zlahka tvori, zlahka prikliče iz spomina itd.

(c) Prototipičnost. Kar je bližje prototipu, je bolj naravno ogovorjenemu. Govorečemu je bližje neprototipično.

(č) Stopnja včlenjenosti v zgradbo. Kar je bolje včlenjeno v svojo zgradbo, je govorečemu bolj naravno. 
(d) Pogostnost. Kar je v nekem jeziku bolj pogostno kot pojavnica, je govorečemu bolj naravno. Kar je za govorečega kognitivno preprostejše, se več rabi. (Toda obratno ne drži: kar je govorečemu naravno, ni nujno pogostno.)

(e) Majhen nasproti velikemu razredu. Raba (enote iz) majhnega razreda je govorečemu bolj naravna kot raba (enote iz) velikega razreda. Med tvorjenjem sporočila govoreči lažje izbira iz majhnih razredov kot iz velikih.

(f) Govorečemu so naravni vsi poteki, le pri premikih velja: premik enote na levo je govorečemu bolj naraven od premika enote na desno. Premik v levo je bolj naraven od nepremika. Premik v desno je manj naraven od nepremika.

(g) Sprejemljiva nasproti nesprejemljivi rabi. Sprejemljivo je govorečemu bolj naravno od nesprejemljivega. Bistveni razlog za sprejemljivost neke skladenjske zgradbe je prav njena večja naravnost za govorečega $v$ primerjavi s soodnosno nesprejemljivo zgradbo.

(h) Kar je bolj razširjeno po jezikih sveta, je govorečemu bolj naravno (tipološko načelo). Kar je za govorečega kognitivno bolj preprosto, se rabi v več jezikih.

Lestvica naravnosti se v najsplošnejši obliki glasi >nat (A, B), kjer sta A in B "vrednosti« lestvice. A se nanaša na ugodno za govorca, B pa na ugodno za ogovorjenega. Dovoljeni sta dve razširjeni lestvici, in sicer $>$ nat $(A+B, B)$ in $>$ nat $(A, A+$ $\mathrm{B})$; razširjeni lestvici sta veljavni, kadar je veljavna soodnosna osnovna lestvica oblike $>$ nat $(\mathrm{A}+\mathrm{B})$.

Lestvice naravnosti se utemeljujejo z gornjimi načeli/merili naravnosti (v nadaljevanju: aksiomi). Navadno zadošča, da se neka lestvica utemelji z enim izmed aksiomov, pri čemer tisti aksiom podpira bodisi vrednost A bodisi vrednost B lestvice; nepodprta vrednost zavzame edino preostalo mesto v lestvici. Seveda se lestvica lahko podpre z več aksiomi. Morebitno nasprotje med aksiomi, s katerimi se podpre neka lestvica, se razreši z uporabo omejitev, ki veljajo za povezovanje aksiomov. Doslej je oblikovanih le malo takih omejitev, ni namreč veliko v tej zvezi merodajnega jezikovnega gradiva.

Lestvice naravnosti so bistveni del t. i. izpeljav, v katerih izraža naravna skladnja svoje napovedi o razmerah v jezikovnem gradivu.

V vsaki izpeljavi igrajo pomembno vlogo pravila povezovanja. Ta pravila uravnavajo povezovanje soodnosnih vrednosti obeh lestvic, ki sta omenjeni v izpeljavi. Povezovanje more biti vzporedno ali križno. Recimo, da sta lestvici >nat (A, B) in $>$ nat $(\mathrm{C}, \breve{C})$. Vzporedno povezovanje poveže vrednost $\mathrm{A} z$ vrednostjo $\mathrm{C}$ in vrednost $\mathrm{B}$ z vrednostjo Č. Križno povezovanje pa poveže A s Č in B s C.

Pomembno vprašanje je, kdaj je povezovanje vzporedno in kdaj križno. Vzporedno povezovanje je privzeta (defaultna) nastavitev. Križno povezovanje nastopi, kadar je jezikovno gradivo izpeljave omejeno na neko nenaravno okolje. Slednje je definirano kot vrednost B lestvice >nat (A, B). Če vsebuje lestvica več kot dve vrednosti, so nenaravne vse vrednosti razen najbolj leve.

Razlikovanje naravne skladnje med vzporednim in križnim povezovanjem izhaja iz dela Henninga Andersena v teoriji zaznamovanosti. Andersen prepoznava v obeh 
vrstah povezovanja nekaj nadjezikovnega, antropološkega. Prim. Andersen 1972: 45, zlasti op. 23.

Sestavki sorodne vsebine: Cvetko Orešnik 2007; Cvetko Orešnik in Orešnik 2007a, b; Orešnik 2006, 2007.

$\mathrm{V}$ tem prispevku bo naravna skladnja ponazorjena s slovenskimi oziralnimi odvisniki. Ko bo kdo o njih prispeval monografijo, bo slednja gotovo med najbolj debelimi knjigami o kakem skladenjskem pojavu slovenščine. Najina ponazoritev pa želi biti kratka, čim bolj preprosta in pregledna. Zajema 18 izpeljav, v katerih so predstavljeni samo izbrani vidiki obravnavane snovi.

Oziralni odvisniki so zaznamovani na več izbirnih načinov. V tem sestavku bo govor pretežno o »oziralnem zaimku « $k i$ in o oziralnem zaimku kateri. Ki je zgolj uvajalo oziralnega odvisnika; nosilec ključnih lastnosti je spremljajoči osebni ali svojilni zaimek (tu imenovan oziralnonavezovalni zaimek): obvezno se navezuje na odnosnico v nadrednem stavku, z odnosnico se (v okviru oblikoslovnih možnosti) ujema v spolu in številu ter je stavčni člen v oziralnem odvisniku. Razloček med $k i$ in kateri je dvojen: 1. Ki stoji obvezno prav na začetku oziralnega odvisnika, medtem ko je stava zaimka kateri manj vezana, npr. ljudje, zelo resno zamišljeni načrti katerih so dobri. 2. Ki nima drugih skladenjskih dolžnosti, namesto njega jih ima oziralnonavezovalni zaimek; kateri pa ima enake skladenjske dolžnosti kot oziralnonavezovalni zaimek. V ki stavku je oziralnost zaznamovana tako s $k i$ kot z oziralnonavezovalnim zaimkom. V kateri stavku je vsa oziralnost zbrana v zaimku kateri.

Za določanje razmerja med $k i+$ oziralnonavezovalni zaimek in zaimkom kateri sta na voljo dve teoretični možnosti: $\mathrm{z}$ ene strani lestvica $>$ nat $(k a t e r i, k i+$ oziralnonavezovalni zaimek), $\mathrm{z}$ druge strani obratna lestvica $>$ nat $(k i+$ oziralnonavezovalni zaimek, kateri). Ker so skladenjski razločki med vrednostima teh lestvic kar veliki, je $\mathrm{z}$ našimi aksiomi med lestvicama težko izbirati. Zato sva poskusila tvoriti izpeljave z obema možnostima. Pri tem se je pokazalo, da odločno več obljublja lestvica >nat ( $k i$ + oziralnonavezovalni zaimek, kateri). Da je res tako, se bo videlo iz izpeljav, ki sledijo. Lestvica je v nekaterih izpeljavah rabljena v polni obliki (pri čemer se ne sme pozabiti, da je lestvica morda sporna), v nekaterih izpeljavah pa samo posredno, $\mathrm{tj}$. po svojih posledicah; slednji sta dve: 1 . okolje »ki+ oziralnonavezovalni zaimek« ne zahteva križnega povezovanja (ker stoji na mestu A lestvice) in 2. okolje »kateri« nasprotno zahteva križno povezovanje (ker stoji na mestu B lestvice).

Gornja lestvica se da podaljšati $\mathrm{v}$ desno, tako da dobimo (za potrebe tega sestavka) >nat ( $k i+$ oziralnonavezovalni zaimek, kateri, oziralno prislovno določilo, $k a k r-$ šen); oziralno prislovno določilo in zaimek kakršen sta še manj naravna kot ki+oziralnonavezovalni zaimek in zaimek kateri ter tvorita vsak zase prav tako nenaravno okolje kot zaimek kateri. Podaljšana lestvica (koristila nam bo pri zadnjih izpeljavah) je urejena po od naju domnevani padajoči pogostnosti posameznih vrednosti.

Okolje $k i+$ oziralnonavezovalni zaimek kot rečeno samo zase ne zahteva križnega povezovanja. Pričakujemo vzporedno povezovanje. Take so res razmere v izpel- 
javah (1) in (2). V izpeljavi (3) pa se uveljavi križno povezovanje, ker je jezikovno gradivo omejeno na nenaravno okolje »odvisni stavek«.

(1) Slovenščina. Oziralnonavezovalni zaimek je lahko svojilni, in sicer tako v pridevniški kot v samostalniški rabi, npr. ljudje, ki njihovo premoženje ocenjujem kot velik zalogaj in ljudje, ki njihovo ocenjujem kot velik zalogaj. Bolj navadno je prvo.

Dvojnici: oziralnonavezovalni svojilni zaimek v samostalniški in pridevniški rabi.

1. Domneve naravne skladnje:

1.1. >nat (pridevniška, samostalniška) / raba

Tj., pridevniška raba svojilnega zaimka je bolj naravna od samostalniške rabe svojilnega zaimka. - Svojilni zaimek v pridevniški rabi je bolje včlenjen v svojo zgradbo kot svojilni zaimek v samostalniški rabi. Po načelu včlenjenosti v zgradbo, točka (č) v seznamu aksiomov.

1.2. >nat (bolj, manj) / pogostno

$\mathrm{Tj}$., bolj pogostno je naravnejše od manj pogostnega. - To je kar načelo pogostnosti, točka (d) v seznamu aksiomov.

2. Pravila vzporednega povezovanja:

2.1. vrednost A teži po povezovanju $\mathrm{z}$ vrednostjo $\mathrm{C}$,

2.2. vrednost B teži po povezovanju z vrednostjo Č.

3. Posledice:

Če jezik loči (v okviru oziralnonavezovalnih svojilnih zaimkov) med samostalniško in pridevniško rabo, tako da je ena bolj, druga manj pogostna, tedaj teži pridevniška raba, da bi bila bolj pogostna, in samostalniška raba teži, da bi bila manj pogostna. Q.E.D. (Ne pričakujemo obratnih razmer.)

4. Opomba. Zgoraj omenjenemu zgledu ljudje, ki njihovo ocenjujem kot velik zalogaj dodajava še nekaj podobnih zgledov: ljudje, ki se po njihovem ne sme hoditi; ljudje, ki na njihovem ne smem zidati; ljudje, ki nič njihovega ne zahtevamo; ljudje, ki do njihovega sega naša njiva.

Izpeljava (1) je uspešna v tem smislu, da napove nekatere vidike jezikovnih razmer, ki so opisane na začetku izpeljave. Izpeljava tudi našteje predpostavke, ki morajo biti izpolnjene, da se dajo zajete jezikovne razmere napovedati. Predpostavke so: uporabljeni jezikovni opis, izbira dvojnic, izbira lestvic naravnosti in izbira pravil povezovanja. (Ta pripomba velja za vse izpeljave.)

(2) Slovenščina. Oziralnonavezovalni zaimek se rabi pogosteje, če ga ne spremlja predlog, kot če je s predlogom (SS00 341), npr. ljudje, ki jih spoštujem nasproti ljudje, ki se brez njih ne bi znašel.

Dvojnici: +/-predlog + oziralnonavezovalni zaimek.

1. Domneve naravne skladnje:

1.1. >nat $(-,+) /$ predlog

Tj., odsotnost predloga je bolj naravna kot njegova navzočnost. - Po načelu najmanjšega napora, točka (b) v seznamu aksiomov. 
1.2. >nat (bolj, manj) / pogostno

Tj., bolj pogostno je naravnejše od manj pogostnega. - To je kar načelo pogostnosti, točka (d) v seznamu aksiomov.

2. Pravila vzporednega povezovanja:

2.1. vrednost $A$ teži po povezovanju $\mathrm{z}$ vrednostjo $\mathrm{C}$,

2.2. vrednost B teži po povezovanju z vrednostjo C̆.

3. Posledice:

Če jezik loči (pri oziralnonavezovalnem zaimku) med rabo s predlogom in brez njega, tako da je ena raba bolj, druga manj pogostna, tedaj teži raba s predlogom, da bi bila manj pogostna, in raba brez predloga teži, da bi bila bolj pogostna. Q.E.D. (Ne pričakujemo obratnih razmer.)

4. Opomba. Prim. izpeljavo (4).

(3) Slovenščina, neknjižna. Ni sprejemljivo človek, ki njega za prepričati mi je zmanjkalo časa, sprejemljivo oziroma polsprejemljivo pa je človek, ki za njega prepričati mi je zmanjkalo časa in človek, ki za prepričati njega mi je zmanjkalo časa.

Dvojnici: ki za prepričati njega in ki za njega prepričati nasproti ki njega za prepričati. - Izpeljava poteka v nenaravnem okolju »odvisni stavek«. V tem primeru je v zgledih odvisni polstavek.

1. Domneve naravne skladnje:

1.1. >nat (tip ki njega za prepričati; tip ki za njega prepričati \& tip ki za prepričati njega)

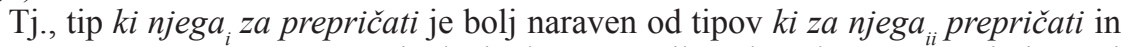
ki za prepričati njega $a_{i i i^{*}}-N j e g a_{i}$ je doživel več premika v levo kot $n j e g a_{i-i i i}$ in je torej bolj naraven po načelu o potekih, točka (f) v seznamu aksiomov. (Na najbolj osnovnem in nepremaknjenem položaju - na mestu premega predmeta - je njega $a_{i i i}$.

1.2. >nat $(+,-)$ / sprejemljivo

Tj., sprejemljivo je bolj naravno od nesprejemljivega. - To je kar načelo sprejemljivosti, točka $(\mathrm{g}) \mathrm{v}$ seznamu aksiomov.

2. Pravila križnega povezovanja:

2.1. vrednost A teži po povezovanju z vrednostjo $\check{C}$,

2.2. vrednost $B$ teži po povezovanju $\mathrm{z}$ vrednostjo $\mathrm{C}$.

3. Posledice:

Če jezik loči med tipom ki njega za prepričati z ene strani in tipoma ki za njega prepričati in ki za prepričati njega z druge strani, tako da je ena možnost (pol)sprejemljiva, druga pa nesprejemljiva, tedaj težita tipa ki za njega prepričati in ki za prepričati njega, da bi bila (pol)sprejemljiva, in tip ki njega za prepričati teži, da ne bi bil sprejemljiv. Q.E.D. (Ne pričakujemo obratnih razmer.)

4. Opombi

4.1. V tej izpeljavi je oziralnonavezovalni zaimek nalašč naglašeni, da bi se izognili morebitni zadregi s stavo naslonk.

4.2. Prim. izpeljavo (13). 
Oziralni zaimek kateri - vzet kot okolje - sam zase potrebuje križno povezovanje, tako res v izpeljavah (4) in (5). Kadar koli imamo opraviti z drugačnim okoljem, se rabi vzporedno povezovanje, tako v izpeljavi (6), ali pa tisto drugačno okolje narekuje križno povezovanje neodvisno od okolja »kateri«, tako v izpeljavi (7):

(4) Slovenščina. Oziralni zaimek kateri se rabi pogosteje, če ga spremlja predlog, kot če je brez predloga (SS00 341), npr. ljudje, brez katerih se ne bi znašel nasproti ljudje, katere spoštujem. teri

Dvojnici: +/-predlog pred kateri. - Izpeljava poteka v nenaravnem okolju »ka-

1. Domneve naravne skladnje:

1.1. >nat $(-,+) /$ predlog

Tj., odsotnost predloga je bolj naravna kot njegova navzočnost. - Po načelu najmanjšega napora, točka (b) v seznamu aksiomov.

1.2. >nat (bolj, manj) / pogostno

Tj., bolj pogostno je naravnejše od manj pogostnega. - To je kar načelo pogostnosti, točka (d) v seznamu aksiomov.

2. Pravila križnega povezovanja:

2.1. vrednost A teži po povezovanju z vrednostjo Č,

2.2. vrednost $B$ teži po povezovanju $\mathrm{Z}$ vrednostjo $\mathrm{C}$.

3. Posledice:

Če jezik loči (pri oziralnem zaimku kateri) med rabo s predlogom in brez njega, tako da je ena raba bolj, druga manj pogostna, tedaj teži raba s predlogom, da bi bila bolj pogostna, in raba brez predloga teži, da bi bila manj pogostna. Q.E.D. (Ne pričakujemo obratnih razmer.)

4. Opomba. Prim. izpeljavo (2).

(5) Slovenščina. Predlog + oziralni zaimek kateri se ne rabi kot prilastek. Ni sprejemljivo načrt, namen brez katerega mi ni znan.

Dvojnici: kateri kot prilastek in kot neprilastek. - Izpeljava poteka v nenaravnem okolju »kateri«.

1. Domneve naravne skladnje:

1.1. $>$ nat $(-,+) /$ predlog

Tj., odsotnost predloga je bolj naravna kot njegova navzočnost. - Po načelu najmanjšega napora, točka (b) v seznamu aksiomov.

Posebni primer od 1.1:

1.1.1. >nat $(-,+/-) /$ predlog

Lestvica je dovoljene razširjene oblike $>$ nat $(A, A+B)$ in je samodejno utemeljena, ker je že utemeljena soodnosna osnovna lestvica 1.1.

1.2. >nat $(-,+) /$ kateri kot prilastek

$\mathrm{Tj}$., neprilastkovna raba oziralnega zaimka kateri je bolj naravna od prilastkovne rabe tega zaimka. - Po načelu pogostnosti, točka (d) v seznamu aksiomov. 
2. Pravila križnega povezovanja:

2.1. vrednost A teži po povezovanju z vrednostjo $\check{C}$,

2.2. vrednost $B$ teži po povezovanju $\mathrm{z}$ vrednostjo $\mathrm{C}$.

3. Posledice:

Če jezik loči med prilastkovno in neprilastkovno rabo oziralnega zaimka kateri, tako da ena možnost dopušča predlog pred zaimkom, druga pa ne, tedaj teži neprilastkovna raba, da bi dopuščala predlog pred zaimkom, in prilastkovna raba teži, da ne bi dopuščala predloga pred zaimkom. Q.E.D. (Ne pričakujemo obratnih razmer.)

4. Opomba. Tudi za oziralnonavezovalni zaimek velja lestvica 1.2. Ki njegov namen, ki njega namen je redko. Prim. izpeljavo (14).

(6) Slovenščina. Oziralnonavezovalni zaimek se lahko navezuje na maksimalno ali na nemaksimalne samostalniške zveze nadrednega stavka, npr. srečal sem [moškega in žensko] , ki so ju, Nemci pozneje ustrelili nasproti srečal sem moškega in žensko, ki so njega in njo $_{3}$ pozneje Nemci ustrelili. Navezovanje na nemaksimalne samostalniške zveze pa ni mogoče, če je v odvisniku oziralni zaimek kateri. Tako JE sprejemljivo srečal sem [moškega in žensko] , katera ${ }_{4}$ so Nemci pozneje ustrelili, NI pa

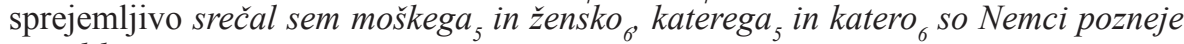
ustrelili.

Dvojnici: navezovanje zaimka kateri na maksimalno in na nemaksimalne samostalniške zveze nadrednega stavka. - Izpeljava zajema tudi odnosnico v nadrednem stavku, ne samo oziralnega odvisnika, tako da ni razloga za križno povezovanje.

1. Domneve naravne skladnje:

1.1. >nat $(+,-)$ / maksimalna samostalniška zveza

Tj., maksimalna samostalniška zveza je bolj naravna kot nemaksimalna samostalniška zveza. - Maksimalnih samostalniških zvez je več kot nemaksimalnih, saj marsikatera maksimalna sploh ne vsebuje nemaksimalnih. Maksimalna samostalniška zveza je torej naravna po načelu pogostnosti, točka (d) v seznamu aksiomov.

1.2. $>$ nat $(+,-) /$ sprejemljivo

Tj., sprejemljivo je bolj naravno od nesprejemljivega. - To je kar načelo sprejemljivosti, točka (g) v seznamu aksiomov.

2. Pravila vzporednega povezovanja:

2.1. vrednost A teži po povezovanju z vrednostjo C,

2.2. vrednost B teži po povezovanju z vrednostjo Č.

3. Posledice:

Če jezik loči, glede na oziralni zaimek kateri, med navezovanjem na maksimalno samostalniško zvezo in navezovanjem na nemaksimalne samostalniške zveze, tedaj teži navezovanje na maksimalno samostalniško zvezo, da bi bilo sprejemljivo, in navezovanje na nemaksimalne samostalniške zveze teži, da ne bi bilo sprejemljivo. Q.E.D. (Ne pričakujemo obratnih razmer.)

4. Opomba. Prim. izpeljavo (9). 
(7) Slovenščina, neknjižna. Sprejemljivo je človeka, za prepričati katerega mi je zmanjkalo časa, nesprejemljivo je človeka, katerega za prepričati mi je zmanjkalo časa.

Dvojnici: sprejemljivi tip za prepričati katerega in nesprejemljivi tip katerega za prepričati. - Izpeljava poteka v nenaravnem okolju »odvisni stavek«. V tem primeru gre za odvisni polstavek.

1. Domneve naravne skladnje:

1.1. >nat (ex, in) / situ kateri

Tj., oziralni zaimek kateri ex situ je bolj naraven kot oziralni zaimek kateri in situ. - Položaj ex situ nastane po premiku enote v levo. To je naravno po načelu o potekih, točka (f) v seznamu aksiomov.

1.2. >nat $(+,-)$ / sprejemljivo

Tj., sprejemljivo je bolj naravno od nesprejemljivega. - To je kar načelo sprejemljivosti, točka (g) v seznamu aksiomov.

2. Pravila križnega povezovanja:

2.1. vrednost A teži po povezovanju z vrednostjo Č,

2.2. vrednost $B$ teži po povezovanju $\mathrm{z}$ vrednostjo $\mathrm{C}$.

3. Posledice:

Če jezik loči med oziralnim zaimkom kateri in situ in ex situ, tako da je ena možnost sprejemljiva, druga pa ne, tedaj teži oziralni zaimek kateri in situ, da bi bil sprejemljiv, oziralni zaimek kateri ex situ pa teži, da ne bi bil sprejemljiv. Q.E.D. (Ne pričakujemo obratnih razmer.)

Če zajema jezikovno gradivo hkrati $k i+$ oziralnonavezovalni zaimek ter zaimek kateri, nastopi vzporedno povezovanje, tako res v izpeljavah (8-10), ali pa neko drugačno okolje zahteva križno povezovanje neodvisno od oziralnonavezovalnega zaimka in zaimka kateri, tako res v izpeljavah (11-14). Podrobnosti:

(8) Slovenščina. $K i+$ oziralnonavezovalni zaimek je v splošnem bolj pogosten kot oziralni zaimek kateri.

Dvojnici: $k i+$ oziralnonavezovalni zaimek in zaimek kateri.

1. Domneve naravne skladnje:

1.1. >nat (oziralnonavezovalni zaimek, kateri)

$\mathrm{Tj}$., oziralnonavezovalni zaimek je bolj naraven kot kateri. - Po načelu najmanjšega napora, točka (b) v seznamu aksiomov.

1.2. >nat (bolj, manj) / pogostno

$\mathrm{Tj}$., bolj pogostno je naravnejše od manj pogostnega. - To je kar načelo pogostnosti, točka (d) v seznamu aksiomov.

2. Pravila vzporednega povezovanja:

2.1. vrednost $A$ teži po povezovanju $z$ vrednostjo $C$,

2.2. vrednost B teži po povezovanju z vrednostjo $\breve{C}$. 


\section{Posledice:}

Če jezik loči med $k i+$ oziralnonavezovalnim zaimkom in oziralnim zaimkom kateri, tako da je eno bolj, drugo pa manj pogostno, tedaj teži ki + oziralnonavezovalni zaimek, da bi bil bolj pogosten, in kateri teži, da bi bil manj pogosten. Q.E.D. (Ne pričakujemo obratnih razmer.)

(9) Slovenščina. $K i+$ oziralnonavezovalni zaimek se lahko navezuje na nemaksimalne samostalniške zveze nadrednega stavka, npr. srečal sem moškega in žensko, ki so $\underline{n j e g a}_{2}$ in $\underline{n j o}_{3}$ pozneje Nemci ustrelili. Navezovanje na nemaksimalne samostalniške zveze pa ni mogoče, če je v odvisniku oziralni zaimek kateri. Tako JE sprejemljivo srečal sem [moškega in žensko], katera ${ }_{4}$ so Nemci pozneje ustrelili, NI pa sprejemljivo srečal sem moškega ${ }_{5}$ in žensko katerega $_{5}$ in katero ${ }_{6}$ so Nemci pozneje ustrelili.

Dvojnici: navezovanje oziralnonavezovalnega zaimka in zaimka kateri na nemaksimalne samostalniške zveze nadrednega stavka. - V izpeljavo je zajeta tudi odnosnica $\mathrm{v}$ nadrednem stavku, zato ni razloga za križno povezovanje.

1. Domneve naravne skladnje:

1.1. >nat (oziralnonavezovalni zaimek, kateri)

Tj., oziralnonavezovalni zaimek je bolj naraven kot kateri. - Po načelu pogostnosti, točka (d) v seznamu aksiomov.

1.2. $>$ nat $(+,-)$ / sprejemljivo

Tj., sprejemljivo je bolj naravno od nesprejemljivega. - To je kar načelo sprejemljivosti, točka (g) v seznamu aksiomov.

2. Pravila vzporednega povezovanja:

2.1. vrednost A teži po povezovanju z vrednostjo $C$,

2.2. vrednost B teži po povezovanju z vrednostjo Č.

3. Posledice:

Če jezik loči (v okviru navezovanja na nemaksimalne samostalniške zveze) med kateri in $k i+$ oziralnonavezovalnim zaimkom, tako da je eno sprejemljivo, drugo pa ne, tedaj teži $k i+$ oziralnonavezovalni zaimek, da bi bil sprejemljiv, in kateri teži, da ne bi bil sprejemljiv. Q.E.D. (Ne pričakujemo obratnih razmer.)

4. Opomba. Prim. izpeljavo (6).

(10) Slovenščina. Oziralnonavezovalni zaimek ne stoji nujno v ki stavku, temveč lahko v kakem še globlje vloženem odvisniku, npr. odeja $a_{l}$, $i$ ti veš, (da jaz vem,) kdo jo ${ }_{l}$ je kupil. Oziralni odvisnik s kateri take možnosti NE dopušča, npr. v zgledu odeja, $k_{\text {katera }}$ ti veš, (da jaz vem,) kdo jo je kupil se naslonka jo navezuje najprej na katera, samo posredno na odeja. Bistveno je navezovanje na odnosnico.

Dvojnici: $k i+$ oziralnonavezovalni zaimek in kateri.

1. Domneve naravne skladnje:

1.1. >nat (oziralnonavezovalni zaimek, kateri)

$\mathrm{Tj}$., oziralnonavezovalni zaimek je bolj naraven kot kateri. - Po načelu najmanjšega napora, točka (b) v seznamu aksiomov.

1.2. >nat (od daleč, od blizu) / navezovanje osebnega zaimka 
Tj., navezovanje osebnega zaimka od daleč je bolj naravno od navezovanja osebnega zaimka od blizu. - Ogovorjeni lažje dekodira navezovanje od blizu, zato mora biti táko navezovanje omenjeno na mestu B lestvice. Po načelu ugodnega za ogovorjenega, točka (a) v seznamu aksiomov.

Posebni primer od 1.2:

1.2.1. >nat (od daleč \& od blizu, samo od blizu) / navezovanje osebnega zaimka

Lestvica je dovoljene razširjene oblike >nat $(\mathrm{A}+\mathrm{B}, \mathrm{B})$ in je samodejno utemeljena, ker je že utemeljena soodnosna osnovna lestvica 1.2.

2. Pravila vzporednega povezovanja:

2.1. vrednost A teži po povezovanju $\mathrm{z}$ vrednostjo $\mathrm{C}$,

2.2. vrednost B teži po povezovanju z vrednostjo C̆.

\section{Posledice:}

Če jezik loči med $k i+$ oziralnonavezovalnim zaimkom in oziralnim zaimkom $\mathrm{ka}$ teri, tako da dopušča ena možnost navezovanje osebnega zaimka od daleč in od blizu, druga možnost pa samo od blizu, tedaj teži $k i+$ oziralnonavezovalni zaimek, da bi dopuščal navezovanje od daleč in od blizu, in kateri teži, da bi dopuščal navezovanje samo od blizu. Q.E.D. (Ne pričakujemo obratnih razmer.)

(11) Slovenščina. S predlogom se pogosteje rabi kateri kot $k i+$ oziralnonavezovalni zaimek, npr. ljudje, brez katerih se ne znajdem nasproti ljudje, ki se brez njih ne znajdem.

Dvojnici: $k i$ + oziralnonavezovalni zaimek in kateri, oba s predlogom. - Izpeljava poteka v nenaravnem okolju »+predlog «, vzetem iz lestvice $>$ nat $(-,+) /$ predlog, utemeljene v izpeljavi (2).

1. Domneve naravne skladnje:

1.1. >nat (oziralnonavezovalni zaimek, kateri)

$\mathrm{Tj}$., oziralnonavezovalni zaimek je bolj naraven kot kateri. - Po načelu najmanjšega napora, točka (b) v seznamu aksiomov.

1.2. >nat (bolj, manj) / pogostno

Tj., bolj pogostno je naravnejše od manj pogostnega. - To je kar načelo pogostnosti, točka (d) v seznamu aksiomov.

2. Pravila križnega povezovanja:

2.1. vrednost A teži po povezovanju z vrednostjo $\check{C}$,

2.2. vrednost $B$ teži po povezovanju $\mathrm{z}$ vrednostjo $\mathrm{C}$.

3. Posledice:

Če jezik loči med predlog + kateri in predlog $+k i+$ oziralnonavezovalni zaimek, tako da je ena možnost bolj, druga pa manj pogostna, tedaj teži predlog + kateri, da bi bilo bolj pogostno, in predlog $+k i+$ oziralnonavezovalni zaimek teži, da bi bilo manj pogostno. Q.E.D. (Ne pričakujemo obratnih razmer.)

(12) Slovenščina. Oziralniška pridevniška zveza (npr. pomemben med katerimi; jedro zveze je pridevnik pomemben). Če se z oziralniško pridevniško zvezo preseli na začetek oziralnega odvisnika tudi njeno pridevniško jedro, je odvisnik samo neo- 
mejevalni, npr. prišli so uradniki $A, B$ in $C$, pomemben med katerimi je samo $A$. NI sprejemljivo: prišli so neki taki uradniki, pomemben med katerimi je samo eden. Če selitve pridevnika ni, je odvisnik lahko omejevalni ali neomejevalni, npr. prišli so uradniki A, B in C, med katerimi je pomemben samo A; prišli so neki taki uradniki, med katerimi je pomemben samo eden.

Dvojnici: omejevalni in neomejevalni oziralni odvisnik. - Izpeljava poteka v nenaravnem okolju »odvisni stavek«.

1. Domneve naravne skladnje:

1.1. >nat (omejevalni, neomejevalni) / oziralni odvisnik

Tj., omejevalni odvisnik je bolj naraven od neomejevalnega. - Neomejevalni odvisnik je dostikrat ločen od nadrednega stavka s kratkim premorom. Torej je omejevalni odvisnik bolje včlenjen $\mathrm{v}$ zgradbo in zato naraven po načelu včlenjenosti $\mathrm{v}$ zgradbo, točka (̌̌) v seznamu aksiomov.

Posebni primer od 1.1:

1.1.1. >nat (omejevalni \& neomejevalni, samo neomejevalni) / oziralni odvisnik

Lestvica je dovoljene razširjene oblike >nat $(A+B, B)$ in je samodejno utemeljena, ker je že utemeljena soodnosna osnovna lestvica 1.1.

1.2. $>$ nat $(+,-)$ / premik jedra pridevniške zveze $v$ levo

$\mathrm{Tj}$., premik jedra $\mathrm{v}$ levo je bolj naraven od nepremika jedra. - Vsak premik v levo je naraven. Po načelu o potekih, točka (f) v seznamu aksiomov.

2. Pravila križnega povezovanja:

2.1. vrednost A teži po povezovanju z vrednostjo $\check{C}$,

2.2. vrednost $\mathrm{B}$ teži po povezovanju $\mathrm{z}$ vrednostjo $\mathrm{C}$.

\section{Posledice:}

Če jezik loči med premikom in nepremikom jedra pridevniške zveze, tako da je ena možnost $\mathrm{v}$ omejevalnih in neomejevalnih oziralnih odvisnikih, druga možnost pa samo v neomejevalnih oziralnih odvisnikih, tedaj teži premik jedra, da bi bil samo v neomejevalnih oziralnih odvisnikih, in nepremik jedra teži, da bi bil v omejevalnih in neomejevalnih oziralnih odvisnikih. Q.E.D. (Ne pričakujemo obratnih razmer.)

(13) Slovenščina. V izpeljavi (7) je omenjena sprejemljivost zgleda človek, za prepričati katerega mi je zmanjkalo časa. Enaka zgradba je precej manj sprejemljiva s $k i+$ oziralnonavezovalnim zaimkom. Tako domala ni sprejemljivo človek, $\underline{k i}$ njega za prepričati mi je zmanjkalo časa in samo malo bolj sprejemljivo človek, ki za njega prepričati mi je zmanjkalo časa in človek, ki za prepričati njega mi je zmanjkalo časa.

Dvojnici: zgradba s kateri in zgradba s $k i+$ oziralnonavezovalnim zaimkom. Izpeljava poteka v nenaravnem okolju »odvisni stavek«. Tu gre za odvisni polstavek.

1. Domneve naravne skladnje:

1.1. >nat (oziralnonavezovalni zaimek, kateri)

$\mathrm{Tj}$., oziralnonavezovalni zaimek je bolj naraven kot kateri. - Po načelu najmanjšega napora, točka (b) v seznamu aksiomov.

1.2. $>$ nat $(+,-) /$ sprejemljivo 
Tj., sprejemljivo je bolj naravno od nesprejemljivega. - To je kar načelo sprejemljivosti, točka (g) v seznamu aksiomov.

Posebni primer od 1.2:

1.2.1. >nat (bolj, manj) / sprejemljivo

Tj., bolj sprejemljivo je naravnejše od manj sprejemljivega. - To je nekoliko ohlapnejši različek od 1.2.

2. Pravila križnega povezovanja:

2.1. vrednost A teži po povezovanju z vrednostjo $\check{C}$,

2.2. vrednost B teži po povezovanju z vrednostjo C.

3. Posledice:

Če jezik loči med zgradbo $\mathrm{s} k i+$ oziralnonavezovalnim zaimkom in zgradbo $\mathrm{s}$ kateri, tako da je ena zgradba bolj sprejemljiva, druga pa manj, tedaj teži zgradba s $k i$ + oziralnonavezovalnim zaimkom, da bi bila manj sprejemljiva, in zgradba s kateri teži, da bi bila bolj sprejemljiva. Q.E.D. (Ne pričakujemo obratnih razmer.)

4. Opombe

4.1. V tej izpeljavi je oziralnonavezovalni zaimek nalašč naglašeni, da bi se izognili morebitni zadregi s stavo naslonk.

4.2. Izpeljava je nenavadna po tem, da pripisuje večjo pogovornost oziralnemu zaimku kateri kot ki+oziralnonavezovalnemu zaimku. V splošnem velja obratno.

4.3. Prim. izpeljavo (3).

(14) Slovenščina. Zgled načrt, katerega namen ni znan in zgled načrt, namen katerega ni znan sta bolj pogostna kot zgled načrt, ki njegov namen ni znan.

Dvojnici: tip katerega namen (namen katerega) in tip njegov namen. - Izpeljava poteka v nenaravnem okolju »prilastkovna raba oziralnega zaimka«. To okolje je vzeto iz lestvice $>$ nat $(-,+) /$ oziralni zaimek kot prilastek. Lestvica je utemeljena $s$ tem, da je neprilastkovna raba oziralnega zaimka odločno bolj pogostna od prilastkovne. Prim. izpeljavo (5).

1. Domneve naravne skladnje:

1.1. >nat (tip njegov namen, tip katerega namen)

$\mathrm{Tj} .$, tip njegov namen je bolj naraven kot tip katerega namen. - Po načelu najmanjšega napora, točka (b) v seznamu aksiomov. Njegov je bolje včlenjen v svojo zgradbo kot katerega, zato je naraven po načelu včlenjenosti v zgradbo, točka (č) v seznamu aksiomov.

1.2. >nat (bolj, manj) / pogostno

Tj., bolj pogostno je naravnejše od manj pogostnega. - To je kar načelo pogostnosti, točka (d) v seznamu aksiomov.

2. Pravila križnega povezovanja:

2.1. vrednost A teži po povezovanju z vrednostjo $\check{C}$,

2.2. vrednost $B$ teži po povezovanju $\mathrm{z}$ vrednostjo $\mathrm{C}$.

3. Posledice: 
Če jezik loči med katerega namen (namen katerega) in njegov namen, tako da je eno bolj, drugo pa manj pogostno, tedaj teži katerega namen (namen katerega), da bi bilo bolj pogostno, in njegov namen teži, da bi bilo manj pogostno. Q.E.D. (Ne pričakujemo obratnih razmer.)

S tem se od $k i+$ oziralnonavezovalnega zaimka in od zaimka kateri še ne poslavljamo, preusmerjamo pa pogled na nadaljnje oziralne prvine, razvidne iz uvodoma že omenjene podaljšane lestvice >nat $(k i+$ oziralnonavezovalni zaimek, kateri, oziralno prislovno določilo, kakršen):

(15) Slovenščina. Samostalniška zveza se ozirali s $k i+$ oziralnonavezovalnim zaimkom ali s kateri. Pridevniška zveza se ozirali s kakršen, npr. (prav taka) deklica, kakršna je/postaja; (prav tak) načrt, za kakršnega ga štejejo/imajo (kot kakršnega ga cenijo).

Dvojnici: samostalniška in pridevniška zveza. - Zajeta je tudi odnosnica v nadrednem stavku, zato ni razloga za križno povezovanje.

1. Domneve naravne skladnje:

1.1. >nat (samostalniška, pridevniška) / zveza

Tj., samostalniška zveza je bolj naravna od pridevniške. - Vsi jeziki imajo samostalnike, medtem ko v vrsti jezikov pridevnikov ni ali so redki. Po tipološkem načelu, točka (h) v seznamu aksiomov.

1.2. >nat $(k i+$ oziralnonavezovalni zaimek \& kateri, kakršen $)$

Tj., $k i+$ oziralnonavezovalni zaimek \& kateri sta bolj naravna kot kakršen. - Po načelu pogostnosti, točka $(\mathrm{d}) \mathrm{v}$ seznamu aksiomov.

2. Pravila vzporednega povezovanja:

2.1. vrednost A teži po povezovanju z vrednostjo $C$,

2.2. vrednost $B$ teži po povezovanju $z$ vrednostjo $\breve{C}$.

3. Posledice:

Če jezik loči med samostalniško in pridevniško zvezo, tako da se ena ozirali s $k i$ + oziralnonavezovalnim zaimkom ali s kateri in druga s kakršen, tedaj teži samostalniška zveza, da bi se oziralila s $k i+$ oziralnonavezovalnim zaimkom ali s kateri, in pridevniška zveza teži, da bi se oziralila s kakršsen. Q.E.D. (Ne pričakujemo obratnih razmer.)

(16) Slovenščina. Če oziralno prislovno določilo kraja izraža mesto ali cilj, se rabi navadno brez predloga, npr. kraj, kjer stojim; kraj, kamor grem. Če pa izraža izhodišče, se rabi s predlogom, npr. kraj, od koder prihajam.

Dvojnici: oziralni prislovni določili kjer in kamor nasproti od koder. - Izpeljava poteka v nenaravnem okolju »oziralno prislovno določilo«. To okolje je vzeto iz lestvice >nat ( $k i+$ oziralnonavezovalni zaimek, kateri, oziralno prislovno določilo, $k a-$ kršen), ki je urejena po padajoči pogostnosti posameznih vrednosti.

1. Domneve naravne skladnje:

1.1. >nat $(-,+) /$ predlog

Tj., odsotnost predloga je bolj naravna kot navzočnost predloga. - Po načelu 
najmanjšega napora, točka (b) v seznamu aksiomov.

1.2. >nat ('izhodišče', 'mesto/cilj')

Tj., 'izhodišče' je bolj naravno kot 'mesto/cilj'. - Ogovorjeni lažje zaznava mesto ali cilj kot izhodišče, zato mora biti 'mesto/cilj' omenjeno na mestu B lestvice. Po načelu ugodnega za ogovorjenega, točka (a) v seznamu aksiomov.

2. Pravila križnega povezovanja:

2.1. vrednost A teži po povezovanju z vrednostjo $\check{C}$,

2.2. vrednost $B$ teži po povezovanju $\mathrm{z}$ vrednostjo $\mathrm{C}$.

3. Posledice:

Če jezik loči (v okviru oziralnih prislovnih določil) med prislovnim določilom s predlogom in brez predloga, tako da ena možnost pomeni 'izhodišče', druga pa 'mesto/cilj', tedaj teži prislovno določilo s predlogom, da bi pomenilo 'izhodišče', in prislovno določilo brez predloga teži, da bi pomenilo 'mesto/cilj'. Q.E.D. (Ne pričakujemo obratnih razmer.)

(17) Slovenščina. Oziralno prislovno določilo od koder pomeni 'prostorsko izhodišče', in takrat se rabi tako $\mathrm{v}$ omejevalnih kot $\mathrm{v}$ neomejevalnih oziralnih odvisnikih, npr. (omejevalno:) tista hiša, od koder so odnesli zlatnino, (neomejevalno:) hiša $A$, od koder so odnesli zlatnino. Prislovno določilo od koder pomeni tudi 'logično izhodišče', in takrat prevladuje neomejevalni oziralni odvisnik, npr. domneva $A$ je potrjena, od koder sledi, da je resnična tudi domneva $B$. Natančneje, pomen 'logično izhodišče' je bolj pogosten v neomejevalnih odvisnikih kot v omejevalnih; npr. tista domneva, od koder sledi, da je resnična tudi domneva $B$ je redko.

Dvojnici: 'prostorsko izhodišče' in 'logično izhodišče'. - Izpeljava poteka v nenaravnem okolju »oziralno prislovno določilo«. To okolje je vzeto iz lestvice >nat ( $k i$ + oziralnonavezovalni zaimek, kateri, oziralno prislovno določilo, kakršen). Izpeljava poteka tudi v nenaravnem okolju »odvisni stavek«.

1. Domneve naravne skladnje:

1.1. >nat (omejevalni, neomejevalni) / oziralni odvisnik

Tj., omejevalni odvisnik je bolj naraven od neomejevalnega. - Neomejevalni odvisnik je navadno ločen od nadrednega stavka s kratkim premorom. Torej je omejevalni odvisnik bolje včlenjen $\mathrm{v}$ zgradbo in zato naraven po načelu včlenjenosti $\mathrm{v}$ zgradbo, točka (̌̌) v seznamu aksiomov.

Posebni primer od 1.1:

1.1.1. >nat (omejevalni \& neomejevalni, samo neomejevalni) / oziralni odvisnik

Lestvica je dovoljene razširjene oblike >nat $(A+B, B)$ in je samodejno utemeljena, ker je že utemeljena soodnosna osnovna lestvica 1.1.

1.2. >nat ('logično izhodišče', 'prostorsko izhodišče')

Tj., 'logično izhodišče' je bolj naravno kot 'prostorsko izhodišče'. - Ogovorjeni lažje opazi prostorsko izhodišče kot logično izhodišče, zato mora biti 'prostorsko izhodišče' omenjeno na mestu B lestvice. Po načelu ugodnega za ogovorjenega, točka (a) v seznamu aksiomov.

2. Pravila križnega povezovanja: 
2.1. vrednost A teži po povezovanju $\mathrm{z}$ vrednostjo $\check{C}$, 2.2. vrednost $\mathrm{B}$ teži po povezovanju $\mathrm{z}$ vrednostjo $\mathrm{C}$.

3. Posledice:

Če jezik loči (v okviru oziralnega prislova od koder) med pomenom 'logično izhodišče' in pomenom 'prostorsko izhodišče', tako da se en pomen rabi v omejevalnih in neomejevalnih oziralnih odvisnikih, drugi pomen pa samo v neomejevalnih oziralnih odvisnikih, tedaj teži pomen 'logično izhodišče', da bi se rabil samo v neomejevalnih oziralnih odvisnikih, in pomen 'prostorsko izhodišče' teži, da bi se rabil $\mathrm{v}$ omejevalnih in neomejevalnih oziralnih odvisnikih. Q.E.D. (Ne pričakujemo obratnih razmer.)

Ker ima oziralnonavezovalne zaimke tudi neknjižna angleščina, dodajava kot zanimivost zgled od tam:

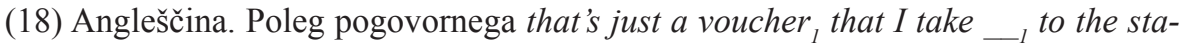
tion 'to je samo vavčer, ki ga nesem na postajo' se rabi še nizko pogovorno that's just a voucher ${ }_{1}$ that I take $\underline{i t}_{1}$ to the station enak pomen, $\mathrm{z}$ oziralnonavezovalnim zaimkom it 'ga' (Carter \& McCarthy 2006: 568). - Znak _ pomeni nezapolnjeno skladenjsko vrzel.

Dvojnici: vrzel nasproti oziralnonavezovalnemu zaimku v oziralnem odvisniku.

1. Domneve naravne skladnje:

1.1. >nat (oziralnonavezovalna vrzel, oziralnonavezovalni zaimek)

$\mathrm{Tj}$., oziralnonavezovalna vrzel je bolj naravna od oziralnonavezovalnega zaimka. - Po načelu najmanjšega napora, točka (b) v seznamu aksiomov.

1.2. >nat (bolj, manj) / pogostno

Tj., bolj pogostno je naravnejše od manj pogostnega. - Po načelu pogostnosti, točka (d) v seznamu aksiomov.

2. Pravila vzporednega povezovanja:

2.1. vrednost A teži po povezovanju z vrednostjo $C$,

2.2. vrednost B teži po povezovanju z vrednostjo Č.

3. Posledice:

Če jezik loči med oziralnonavezovalno vrzeljo in oziralnonavezovalnim zaimkom, tako da je ena možnost bolj, druga pa manj pogostna, tedaj teži oziralnonavezovalna vrzel, da bi bila bolj pogostna, in oziralnonavezovalni zaimek teži, da bi bil manj pogosten. Q.E.D. (Ne pričakujemo obratnih razmer.)

\section{Za konec}

Gornja ponazoritev priča, da naravna skladnja zmore napovedati célo vrsto jezikovnih razmer, pri čemer se naslanja na le malo predpostavk (tj., na konkretni opis jezikovnih podatkov, na izbiro dvojnic, na lestvice naravnosti, na pravila povezovanja) in na skromen aparat (namreč na format izpeljav). Kot pretežno v oblikoslovju in drugače kot $\mathrm{v}$ tvorbeni skladnji so napovedi plitve $\mathrm{v}$ tem smislu, da nobena napoved 
ne sledi iz kake druge napovedi.

Razvijanje naravne skladnje se bo nadaljevalo kot pregledovanje karseda različnega jezikovnega gradiva; posebna pozornost bo (tudi poslej) posvečena slovenščini.

\section{Seznam navedenk}

Andersen, Henning. 1972. "Diphthongization," Language 48: 11-50.

Carter, Ronald, in McCarthy, Michael. 2006. Cambridge grammar of English. Cambridge: Cambridge University Press.

Cvetko Orešnik, Varja. 2007. "Skladenjska posebnost starinskega ali narečnega slovenskega namenilnika," Slavistična revija 55: 257-60. = Zbornik v čast akademiku Jožetu Toporišiču.

Cvetko Orešnik, Varja, in Orešnik, Janez. 2007a. "Natural Syntax: Three-value naturalness scales," Slovenski jezik / Slovene Linguistic Studies 6: 235-49.

Cvetko Orešnik, Varja, in Orešnik, Janez. 2007b. "Povedkovo določilo v naravni skladnji slovenščine," Jezikoslovni zapiski 13: 103-16. = Merkujev zbornik.

Havers, Wilhelm. 1931. Handbuch der erklärenden Syntax. Heidelberg: Winter.

Orešnik, Janez. 2006. "Slovenski trpnik z deležnikom (v naravni skladnji)" 26-34 v Jesenšek, Marko, in Zorko, Zinka. 2006. Jezikovna predanost. Akademiku prof. dr. Jožetu Toporišiču ob 80-letnici. Maribor: Slavistično društvo Maribor. Ljubljana: SAZU.

Orešnik, Janez. 2007. "Slovenski trpnik na SE (v naravni skladnji)", Slavistična revija 55: 31-39. = Zbornik v čast akademiku Jožetu Toporišiču.

SS00 $=$ Toporišič 2000

Toporišič, Jože. 2000. Slovenska slovnica, četrta izdaja. Maribor: Obzorja.

Prispelo novembra 2008, sprejeto januarja 2009

Received November 2008, accepted January 2009

\section{Slovenski oziralni zaimki v naravni skladnji}

Naravna skladnja (veja teorije naravnosti) določa predpostavke, s katerimi se dajo napovedati naslednje razmere $\mathrm{v}$ slovenskih oziralnih odvisnikih (oštevilčenje ponavlja oštevilčenje izpeljav v glavnem besedilu):

(1) Svojilni oziralnonavezovalni zaimek se lahko rabi kot pridevnik ali kot samostalnik.

(2) V besedilih je raba oziralnonavezovalnega zaimka brez predloga bolj pogostna kot s predlogom.

(3) Raba oziralnonavezovalnega zaimka v pogovornih nedoločniških polstavkih.

(4) V besedilih je raba kateri s predlogom bolj pogostna kot brez predloga.

(5) Predlog + kateri se ne rabi kot prilastek.

(6) Kateri se ne more nanašati na nemaksimalne samostalniške zveze v vlogi odnosnice.

(7) Raba kateri v pogovornih nedoločniških polstavkih. 
(8) Navezovalnooziralni zaimek je v besedilih bolj pogosten kot kateri.

(9) Drugače kot kateri se oziralnonavezovalni zaimek lahko nanaša na nemaksimalne samostalniške zveze v vlogi odnosnice.

(10) Navezovalnooziralni zaimek lahko sledi oziralnemu zaimku v bolj vgnezdenem stavku.

(11) V besedilih je predlog + kateri bolj pogosten kot predlog + oziralnonavezovalni zaimek.

(12) Jedro relativizirane pridevniške zveze se premika različno v omejevalnih in neomejevalnih oziralnih odvisnikih.

(13) V nedoločniških polstavkih pogovornih besedil je oziralnonavezovalni zaimek manj pogosten kot kateri.

(14) V besedilih je prilastkovna raba kateri bolj pogostna kot (svojilni) oziralnonavezovalni zaimek.

(15) Relativizirana pridevniška zveza se glasi kakršen.

(16) Oziralni prislov kraja se rabi brez predloga v pomenu 'položaj v prostoru' ali 'cilj', in s predlogom v pomenu 'prostorsko izhodišče'.

(17) Pomena 'prostorsko izhodišče' in 'logično izhodišče' prislovnega določila od koder.

(18) Navezovalnooziralni zaimek v pogovorni angleščini.

Lestvice naravnosti izhajajo iz osnovnih meril (ali aksiomov), naštetih na začetku prispevka. Napovedi se izračunavajo v t. i. izpeljavah, katerih glavne prvine so par lestvic naravnosti in pravila o povezovanju soodnosnih vrednosti naravnosti. Uporabljata se vzporedno in križno povezovanje, $\mathrm{v}$ dopolnjevalni razvrstitvi. (Obliko)skladenjske razmere so predstavljene v obliki med seboj primerljivih dvojnic.

\section{Slovenian Relative Clauses in Natural Syntax}

Natural Syntax (a branch of Naturalness Theory) defines presuppositions with whose help the following states of affairs in Slovenian relative clauses can be predicted (the numbering recapitulates the numbering of the deductions in the main text):

(1) The possessive resumptive pronoun can be used adjectivally or as a noun.

(2) With the resumptive pronoun the use without a preposition is more frequent tokenwise than the use with a preposition.

(3) The use of the resumptive pronoun in substandard infinitive clauses.

(4) With kateri the use with a preposition is more frequent tokenwise than the use without a preposition.

(5) Preposition + kateri cannot be used attributively.

(6) Kateri cannot refer to non-maximal antecedent noun phrases.

(7) The use of kateri in substandard infinitive clauses.

(8) The resumptive pronoun is more frequent tokenwise than kateri.

(9) Unlike kateri the resumptive pronoun can refer to non-maximal antecedent noun phrases.

(10) The resumptive pronoun can follow the relative in a more deeply embedded clause.

(11) Preposition + kateri is more frequent tokenwise than preposition + resumptive 
pronoun.

(12) The head of the relativized adjective phrase moves differently in defining and non-defining relative clauses.

(13) The resumptive pronoun is less frequent tokenwise than kateri in substandard infinitival clauses.

(14) In attributive use kateri is more frequent tokenwise than the (possessive) resumptive pronoun.

(15) The relativized adjective phrase is kakršen.

(16) The relative adverb of place is used without a preposition to mean 'spatial location' or 'goal', and with a preposition to mean 'spatial source'.

(17) The 'spatial source' and the 'logical source' readings of od koder.

(18) The resumptive pronoun in substandard English.

The naturalness scales follow from the basic parameters (or "axioms") enumerated at the beginning of the paper. Predictions are calculated in the so-called deductions, whose chief elements are a pair of naturalness scales and the rules governing the alignment of corresponding naturalness values. Parallel and chiastic alignments are distinguished, in complementary distribution. 